\title{
Predictive Value of BI-RADS Category 4A and 4B Lesions Detected on Breast Ultrasonography: Single Center Experience
}

\author{
Eun Young Kim*, Hyun Soo Bae*, Sung Ryol Lee, Ji-sup Yun, Yong Lai Park, Chan Heun Park \\ Department of Surgery, Kangbuk Samsung Hospital, Sungkyunkwan University School of Medicine, Seoul, Korea
}

Received October 30, 2020 Revised November 9, 2020 Accepted November 11, 2020

\begin{abstract}
Purpose: The malignancy rates within the Breast Imaging Reporting and Data System (BI-RADS) category $4 \mathrm{a}$ and $4 \mathrm{~b}$ lesions were examined, and the correlations with the histopathology results were analyzed. In addition, the positive predictive value (PPV) and clinical utility of BIRADS category $4 \mathrm{a}$ and $4 \mathrm{~b}$ lesions for predicting a malignancy were assessed.

Methods: From January 2017 to December 2019, patients with BI-RADS category 4a and $4 \mathrm{~b}$ lesions on breast ultrasonography (US) who underwent a subsequent core needle biopsy in the authors' institution were evaluated. The clinical, pathological, and sonographic features were assessed to identify the malignancy rate and pathologic factors predictive of malignancy. The sensitivity, specificity, PPV, and negative predictive value (NPV) were calculated. A Binary logistic regression test was used to estimate the odds ratio (OR) and 95\% confidence interval (CI).

Results: The study population included 314 lesions in 275 patients (mean age, 45.3 years; range, 21-78 years). The overall malignancy rate was $9.8 \%$ (31 of 314). The malignancy rates among the BI-RADS category $4 \mathrm{a}$ and $4 \mathrm{~b}$ lesions were $9.3 \%$ (28 out of 300 ) and $21.4 \%$ (3 out of 14), respectively. Compared to the well-defined margins, ill-defined margins were associated with an increased risk of breast cancer with a corresponding OR (95\% CI) of 1.880 (1.304-2.554). The sensitivity, specificity, PPV, and NPV of the C4a and C4b lesions were as follows: $90.3 \%, 3.9 \%, 9.4 \%$, and $78.6 \%$, respectively, for C4a lesions and, $9.7 \%$, $96.1 \%, 21.4 \%$, and $90.6 \%$, respectively, for C4b lesions. Only the equivocal elasticity on ultrasonography was associated with an increased risk of breast cancer with an OR (95\% CI) of 2.357 (1.004-5.532).

Conclusion: BI-RADS categories $4 \mathrm{a}$ and $4 \mathrm{~b}$ are useful for predicting malignancy. Nevertheless, further studies will be needed to identify more predictive factors for breast cancer.
\end{abstract}

Keywords: Breast imaging reporting data system, Breast neoplasm, Ultrasonography

\section{INTRODUCTION}

Breast cancer is the most common malignancy in women worldwide (1) and mammography is the gold standard for breast cancer screening in South Korea.(2) The Korean radiology committee recommends biannual screening mammography in asymptomatic women aged 40 to 69 years.(3)
Symptomatic and high-risk women are offered complementary measures including ultrasonography (US) and clinical breast examination under clinical supervision. The pitfall of mammography is that it has low accuracy for predicting malignancy in patients with dense breasts.

US is an additional diagnostic tool for young women with dense breasts. US increases the accuracy of breast cancer 
detection by describing the shape of masses. Breast Imaging Reporting and Data System (BI-RADS) was introduced by the American College of Radiology in 1993 to standardize US reports. The BI-RADS system is structured to assess malignancy risk and suggest follow-up steps, including biopsy or frequent radiology follow-ups. Criteria for assessing breast lesions includes: shape (round, oval, or irregular), contours (well-defined, ill-defined, angular, microlobulated, or spiculated), and echogenicity (non-echogenic, hyper-echogenic, isoechoic, or complex). There are seven BI-RADS categories. Among these categories, category 4 is suspected to have malignant changes, and biopsy is recommended. The risk of cancer is between 2 and 94\% for patients within $\mathrm{C} 4$ category. BI-RADS category 4 lesions are further classified into $4 \mathrm{a}, 4 \mathrm{~b}$, and $4 \mathrm{c}$ subcategories.(4) Category $4 \mathrm{a}$ and $4 \mathrm{~b}$ has a probability of malignancy ranging from $2 \%$ to $10 \%$ and $10 \%$ to $50 \%$, respectively.(5) Therefore, histopathologic verification is necessary to determine the accuracy of BI-RADS category $4 \mathrm{a}$ and $4 \mathrm{~b}$ classifications.

In this study, we investigated the predictive value of BI-RADS category $4 \mathrm{a}$ and $4 \mathrm{~b}$ lesions and correlate with histopathologic results. We further assessed clinical features predictive of malignancy.

\section{METHODS}

\section{Study population}

From January 2017 to December 2019, patients with BI-RADS category $4 \mathrm{a}$ and $4 \mathrm{~b}$ lesions on breast US who underwent subsequent core needle biopsy in our institution were included. Patients who underwent stereotactic biopsies or open surgical excisional biopsies with histopathologic confirmation were excluded. Finally, 314 BI-RADS category $4 \mathrm{a}$ and $4 \mathrm{~b}$ lesions in 275 women were included in this study. Patients were characterized based on clinical characteristics such as age at diagnosis, menopausal status (premenopausal vs postmenopausal), method of detection (screen vs symptomatic such as palpability, breast pain, nipple discharge), previous history of breast cancer, and family history of breast cancer. This retrospective study was approved by the
Institutional Review Board (KBSMC2020-10-002).

\section{US examination}

US was performed using an IU22 (Philips Medical Systems, Bothell, USA) or an Aixplorer (SuperSonic Imagine, Aix-en-Provence, Provence-Alpes-Cote d'Azur, France) equipped with a $12-5-\mathrm{MHz}$ linear-array transducer. The longest diameter of mass on the longitudinal view of US was measured. BI-RADS category $4 \mathrm{a}$ and $4 \mathrm{~b}$ lesions were assessed using Doppler US and elasticity scores. Doppler criteria including lesion size, presence or absence of blood vessels, and degree of vascularity compared with the surrounding normal tissue were evaluated. The same radiologist performed elastography followed by core needle biopsies. Elasticity scores were recorded according to the BI-RADS lexicon as negative, equivocal, or positive. $(4,6)$ Masses were characterized based on their sonographic characteristics, such as size, site, location, margin, shape, elasticity, and increased vascular flow on Doppler US.

\section{Ultrasonography-guided biopsy techniques}

All BI-RADS category $4 \mathrm{a}$ and 4 blesions were histologically evaluated using 14-gauge needle core biopsy (TSK Ace-cut, Surecut, Stericut; Create Medic Co. Ltd., Yokohama, Japan). At least five specimens from different areas of the lesion were obtained, and each specimen was at least $1 \mathrm{~cm}$ long. All core needle biopsies were performed by breast radiologists.

\section{Histopathologic analysis}

All specimens were obtained using core needle biopsies, fixed in 10\% formaldehyde solution, and embedded in paraffin. Formalin-fixed paraffin-embedded specimens were cut into $3-\mu \mathrm{m}$-thick sections for hematoxylin and eo$\sin (H \& E)$ and immunohistochemical staining techniques. All results were based on postoperative histopathologic reports of core biopsy specimens. Noncancerous (benign) lesions were defined according to the 2012 World Health Organization (WHO) classification of tumors of the breast.(7) Cancerous lesions were characterized based on 
pathologic characteristics such as size of invasive tumor, size of in situ tumor, and American Joint Committee on Cancer (AJCC) TNM stage. H\&E stained slides from all patients were reviewed by pathologists. Following biopsy of cancerous lesions, all patients underwent surgery of either mastectomy or wide excision with Sentinel Lymph Node Biopsy. The invasive group also included cases of microinvasion.

\section{Statistical analysis}

Categorical data were summarized using frequencies and percentages. A Binary logistic regression test was used to calculate the odds ratio (OR) of malignancy. Results were calculated with 95\% confidence intervals (CIs). All statistical analyses were performed using SPSS for Windows 24.0 (SPSS Inc, Chicago, IL, USA). P values < 0.05 were considered statistically significant.

\section{RESULTS}

Two hundred seventy five women with 314 breast lesions

Table 1. Clinical Characteristics of Study Population

\begin{tabular}{lc}
\hline \multicolumn{1}{c}{ Variables } & Value \\
\hline Age (years) & $45.3 \pm 9.9$ \\
Menopausal status & $245(78.0 \%)$ \\
Premenopausal & $69(22 \%)$ \\
Postmenopausal & \\
Purpose of detection & $229(72.9 \%)$ \\
Screen & $85(27.1 \%)$ \\
Symptomatic (palpability, pain, discharge) & $8(2.5 \%)$ \\
Previous history of breast cancer & $32(10.2 \%)$ \\
Family history of breast cancer &
\end{tabular}

Data are presented as mean (standard deviation) or number (percentage). were included in analysis. The mean age attime of enrollment was $45.3 \pm 9.9$ years (range 21-78). Sixty-nine patients (22.0\%) were postmenopausal, and most breast masses (72.9\%) were asymptomatic detected by screening. Eight patients (2.5\%) had a previous history of breast cancer, and 32 patients (10.2\%) had family history of breast cancer (Table 1).

The histologic findings of the 314 breast lesions are summarized in Table 2. The mean size of BI-RADs C4a and C4b lesions was $1.24 \pm 0.7 \mathrm{~cm}$ (range $0.4-7.5 \mathrm{~cm}$ ). Among 314 breast lesions, 10 were invasive ductal carcinoma (IDC) and 21 were ductal carcinoma in situ (DCIS). Mean size of IDC and DCIS was $3.77 \pm 3.7 \mathrm{~cm}$ (range $4-7.5 \mathrm{~cm}$ ) and $2 \pm 2.4$ $\mathrm{cm}$ (range $0.3-7 \mathrm{~cm}$ ), respectively. There were 283 benign lesions. Mean size of benign lesion was $1.28 \pm 0.76 \mathrm{~cm}$ (range $0.4-7.2 \mathrm{~cm}$ ). Of the 21 DCIS lesions, the most common architectural pattern was cribriform (66.7\%, 14/21). Other typesincluded solid $(23.8 \%, 5 / 21)$ and comedo $(9.5 \%$, 2/21).

Accuracy of BI-RADS C4a and C4b lesions are described

Table 2. Pathologic Characteristics of Breast Malignancy

\begin{tabular}{lc}
\hline \multicolumn{1}{c}{ Malignant } \\
\hline Size of invasive tumor $(\mathrm{cm})$ & $3.77 \pm 3.7$ \\
Size of in situ tumor $(\mathrm{cm})$ & $2.0 \pm 2.4$ \\
Ductal carcinoma in situ & $21(6.7)$ \\
Invasive ductal carcinoma & $10(3.2)$ \\
AJCC TNM stage & \\
pTisN0 & $20(6.4)$ \\
pTisNx & $1(0.3)$ \\
pT1miN0 & $4(1.3)$ \\
pT1aN0 & $2(0.6)$ \\
pT1bN0 & $4(1.3)$ \\
\hline
\end{tabular}

Data are presented as mean (standard deviation) or number (percentage).

AJCC $=$ American Joint Committee on Cancer.

Table 3. Sensitivity, Specificity, PPV, NPV of Category $4 a$ and $4 b$ Lesions

\begin{tabular}{cccccc}
\hline & Malignant & Sensitivity $(95 \% \mathrm{CI})$ & Specificity $(95 \% \mathrm{CI})$ & PPV\% (95\% CI) & NPV\% (95\% CI) \\
\hline C4a & $28(9.4)$ & $90.3(79.9-100.0)$ & $3.9(1.7-6.2)$ & $9.4(6.1-12.8)$ & $78.6(57.1-100.0)$ \\
C4b & $3(21.4)$ & $9.7(0.0-20.1)$ & $96.1(93.8-98.3)$ & $21.4(0.01-42.9)$ & $90.6(87.2-93.9)$ \\
\hline
\end{tabular}

Data are presented as number (percentage).

$\mathrm{PPV}=$ positive predictive value $\mathrm{NPV}=$ negative predictive value; $\mathrm{CI}=$ confidence interval. 
Table 4. Sonographic Characteristics of Malignant Lesions

\begin{tabular}{|c|c|c|c|c|}
\hline Variables & Total & Benign & Malignant & P-value \\
\hline $\mathrm{n}$ & 314 & 283 & 31 & \\
\hline Size of tumor $(\mathrm{cm})$ & $1.25 \pm 0.74$ & $1.28 \pm 0.76$ & $0.99 \pm 0.38$ & 0.001 \\
\hline Margin & & & & 0.923 \\
\hline Well defined (circumscribed) & 75 (23.9) & $67(23.7)$ & $8(25.8)$ & \\
\hline Ill-defined & $200(63.7)$ & $180(63.6)$ & $20(64.5)$ & \\
\hline Microlobulated & $39(12.4)$ & $36(12.7)$ & $3(9.7)$ & \\
\hline Shape & & & & 0.858 \\
\hline Oval & $122(38.9)$ & $111(39.2)$ & $11(35.5)$ & \\
\hline Round & $51(16.2)$ & $45(15.9)$ & $6(19.4)$ & \\
\hline Irregular (including spiculated) & $141(44.9)$ & $127(44.9)$ & $14(45.2)$ & \\
\hline Elasticity & & & & 0.124 \\
\hline Negative & $240(76.4)$ & $220(77.7)$ & $20(64.5)$ & \\
\hline Equivocal & $51(16.2)$ & $42(14.8)$ & $9(29)$ & \\
\hline Positive & $23(7.3)$ & $21(7.4)$ & $2(6.5)$ & \\
\hline Increased vascular flow on doppler US & & & & 0.489 \\
\hline Negative & $290(92.4)$ & $260(91.9)$ & $30(96.8)$ & \\
\hline Positive & 24 (7.6) & $23(8.1)$ & $1(3.2)$ & \\
\hline
\end{tabular}

Data are presented as mean \pm standard deviation or number (percentage).
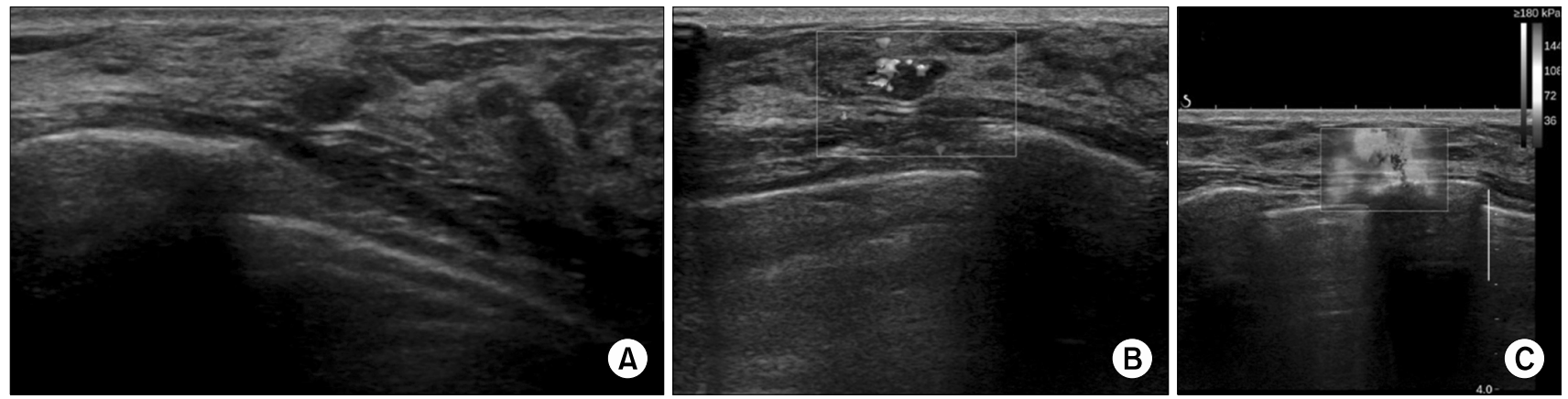

Fig. 1. An asymptomatic 40-year-old woman presented for breast USG. (A) USG revealed a 5-mm oval mass with ill-defined margins on her right upper outer quadrant. (B) Elastography showed equivocal elasticity. (C) The lesion demonstrated increased vascularity on color Doppler USG. The mass was categorized as BI-RADS category 4a. Pathology showed multifocal microinvasive carcinoma. The size of invasive component was $300 \mu \mathrm{m}$ and the in situ component was $40 \mathrm{~mm}$.
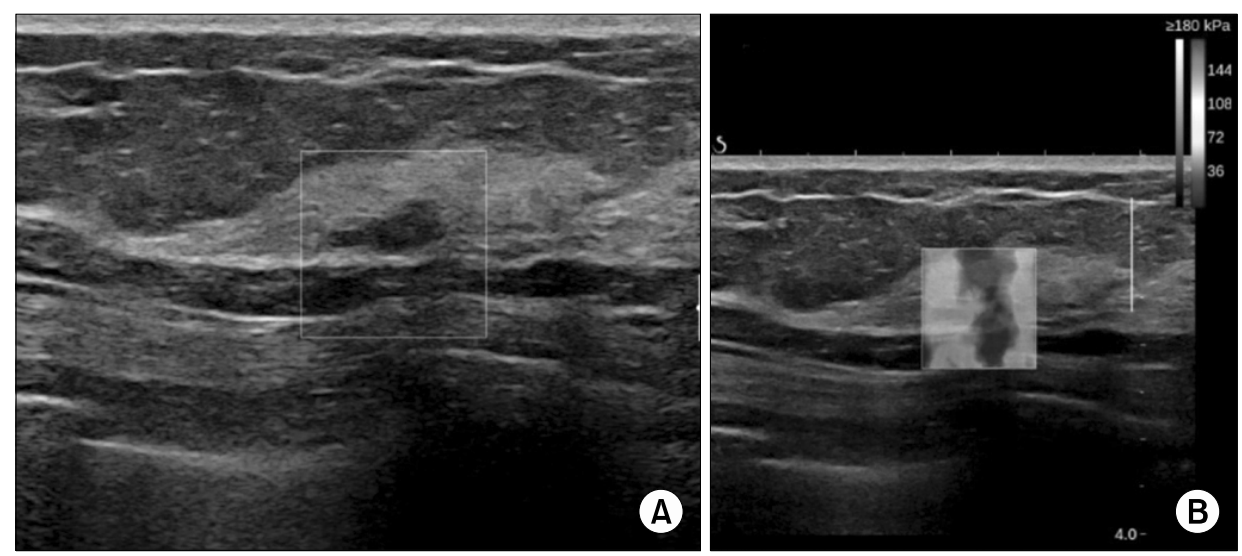

Fig. 2. A 53-year-old woman presented for routine check-up. (A) USG showed an approximately $10-\mathrm{mm}$ hypoechoic mass with ill-defined margins on her right upper outer breast. (B) Elastography revealed positive elasticity results. The mass was assessed as BI-RADS category $4 \mathrm{~b}$ and histopathology confirmed microinvasive carcinoma. The size of invasive component was $480 \mu \mathrm{m}$ and the in situ component was $75 \mathrm{~mm}$. 
in Table 3. Among 300 BI-RADSC4a lesions, 28 were confirmed as malignancy. Among 14 BI-RADS C4b lesions, 3 were confirmed as malignancy. Sensitivity, specificity, PPV, NPV of Category $4 \mathrm{a}$ and $4 \mathrm{~b}$ lesions are as follows. For C4a lesions, the values are 90.3\%, 3.9\%, 9.4\% and 78.6\%, respectively. For C $4 \mathrm{~b}$ lesions, the values are 9.7\%, 96.1\%, $21.4 \%$ and $90.6 \%$, respectively.

The sonographic findings of the 31 breast malignant lesions are presented in Table 4 . The most common type of margin was ill-defined $(n=20,64.5 \%)$. Other types include

Table 5. Analysis of Predictors for Malignancy in BI-RADS C4a and C4b Lesions Using Univariate Logistic Regression Models

\begin{tabular}{|c|c|c|}
\hline Variables & Unadjusted OR (95\% CI) & P value \\
\hline \multicolumn{3}{|l|}{ Age } \\
\hline$<50$ & 1.00 & \\
\hline$\geq 50$ & $1.770(0.829-3.779)$ & 0.140 \\
\hline \multicolumn{3}{|l|}{ Method of detection } \\
\hline Asymptomatic & 1.00 & \\
\hline Symptomatic & $0.488(0.181-1.315)$ & 0.156 \\
\hline \multicolumn{3}{|l|}{ Menopausal status } \\
\hline Premenopausal & 1.00 & \\
\hline Postmenopausal & $1.520(0.665-3.474)$ & 0.320 \\
\hline \multicolumn{3}{|c|}{ Personal history of breast cancer } \\
\hline No & 1.00 & \\
\hline Yes & $1.314(0.156-11.047)$ & 0.801 \\
\hline \multicolumn{3}{|l|}{ Family history of breast cancer } \\
\hline No & 1.00 & \\
\hline Yes & $1.349(0.440-4.136)$ & 0.600 \\
\hline \multicolumn{3}{|l|}{ Size of mass $(\mathrm{cm})$} \\
\hline$<1$ & 1.00 & \\
\hline$\geq 1$ & $0.790(0.376-1.661)$ & 0.534 \\
\hline \multicolumn{3}{|l|}{ Margin } \\
\hline Well defined (circumscribed) & 1.00 & \\
\hline Ill defined & $0.931(0.391-2.214)$ & 0.871 \\
\hline Microlobulated & $0.698(0.174-2.795)$ & 0.611 \\
\hline \multicolumn{3}{|l|}{ Shape } \\
\hline Oval & 1.00 & \\
\hline Round & $1.345(0.469-3.858)$ & 0.581 \\
\hline Irregular (including spiculated) & $1.112(0.485-2.550)$ & 0.801 \\
\hline \multicolumn{3}{|c|}{ Elasticity } \\
\hline Negative & 1.00 & \\
\hline Equivocal & $2.357(1.004-5.532)$ & 0.049 \\
\hline Positive & $1.048(0.229-4.794)$ & 0.952 \\
\hline \multicolumn{3}{|c|}{ Increased vascular flow on doppler US } \\
\hline Negative & 1.00 & \\
\hline Positive & $0.377(0.049-2.889)$ & 0.348 \\
\hline
\end{tabular}

BI-RADS = breast imaging reporting and data system; OR $=$ odds ratio; $\mathrm{CI}=$ confidence interval; US = ultrasonography. well-defined (circumscribed) $(\mathrm{n}=8,25.8 \%)$ and microlobulated $(n=3,9.7 \%)$. The most common type of shape was irregular (including spiculated) $(n=14,45.1 \%)$. Other types were oval $(n=11,35.5 \%)$ and round $(n=6,19.4 \%)$. On elastography, most lesions showed negative elasticity $(n=20$, 64.5\%) and other lesions showed equivocal elasticity $(n=9$, $20.0 \%$ ) and positive elasticity $(n=2,6.5 \%)$. On Doppler US, $96.8 \%$ of lesions $(n=30)$ showed negative vascular flow and only 3.2\% ( $n=1)$ showed increased vascularity. Size of mass was statisctically significant value between benign and malignancy. Sonographic features of BI-RADS $4 \mathrm{a}$ and $4 \mathrm{~b}$ lesions are shown in Figs. 1 and 2.

Univariate analyses were performed to determine factors associated with malignancy risk (Table 5). Older age ( $\geq 50)$ and symptomatic detection of mass such as palpability, breast pain, nipple discharge, postmenopausal status, past or family history of breast cancer, large mass size $(\geq 1 \mathrm{~cm})$, margin and shape of mass, and increased vascular flow on US were not statistically significant risk factors for breast cancer (all $\mathrm{P}>\mathrm{0}$.05). Compared to negative elasticity, equivocal elasticity was associated with risk of malignancy (OR 2.357, 95\% CI 1.004-5.532, $\mathrm{P}=0.049$ ).

\section{DISCUSSION}

In this study, BI-RADS category $4 \mathrm{a}$ and $4 \mathrm{~b}$ lesions were correlated with histopathologic results and US findings to determine predictive factors for breast cancer. The malignancy rate of BI-RADS category $4 \mathrm{a}$ and $4 \mathrm{~b}$ lesions was 9.9\% (31/314), and equivocal elasticity was significant risk factors for malignancy. Current guidelines recommend biopsy for BI-RADS category $\geq 4$ lesions to rule out malignancy. However, these results yield high false positive rates and low positive predictive value (PPV). Category 4 lesions have a low probability of malignancy and are further subcategorized based on their shape, margin, and echogenicity. Three subcategories, 4A, 4B, and $4 \mathrm{C}$ have positive predictive values of $7.6 \%$ (range $2-10$ ), $37.8 \%$ (range 10-50), and 81.9\% (50-95), respectively.(8)

Assessment of sonographic features of BI-RADS cat- 
egory 4 lesions has been validated by several studies. $(5,9)$ Elverici et al.(10) performed a study on 186 BI-RADS category 4 lesions and showed that malignancy rate in subcategory $4 \mathrm{a}, 4 \mathrm{~b}$, and $4 \mathrm{c}$ was $19.5 \%, 41.5 \%$, and $74.3 \%$, respectively. Yoon et al.(8) reported that PPV for malignancy in subcategory $4 \mathrm{a}, 4 \mathrm{~b}$, and $4 \mathrm{c}$ was $7.6 \%, 67.8 \%$, and $81.9 \%$, respectively.

There are known suspicious sonographic features predictive of malignancy such as mass size, elasticity, increased vascularity, shape of margin, and microcalcifications.(11) In our study, equivocal elasticity was a predictor of malignancy. Real-time US elastography is an imaging technique to assess soft tissue strain and provide structural information.(12) It can be used to differentiate between benign and malignant lesions based on their elasticity. Benign lesions have elasticity similar to that of the surrounding tissue, while malignant lesions are harder than adjacent tissue.(6) Mohamed and Abo-Dewan (13) reported that US elastography had sensitivity of $98.41 \%$, specificity of $96.34 \%$, PPV of $95.38 \%$, NPV of $98.75 \%$, and accuracy of $97.24 \%$ for detecting malignancy. Ikeda et al.(14) reported that US elastography had sensitivity of $93.9 \%$, specificity of $88.3 \%$, and accuracy of $90.6 \%$ for all breast lesions. In our study, $15.3 \%$ (46/300) and 7.3\% (22/300) of category 4 a lesions, $35.7 \%$ (5/14) and 7.1\% (1/14) of category $4 \mathrm{~b}$ lesions showed equivocal and positive elasticity, respectively. However, on univariate logistic regression analysis, positive elasticity was not a predictor of malignancy.

Discordant PPV result of BI-RADS $4 \mathrm{a}$ and $4 \mathrm{~b}$ lesions for predicting malignancy exist due to interobserver-variability. $(8,15,16)$ Even though BI-RADS category provides major and minor findings suspicious for malignancy, there are no specific guideline for which finding is included in which category. So there could be intra or interobserver variability for describing BI-RADS $4 \mathrm{a}$ and $4 \mathrm{~b}$ lesions. To solve this problem, Stavros et al.(17) suggested that only two BI-RADS 4 subcategories needed to decrease interobserver variability. Further investigations are needed to better discriminate BI-RADS C4a and C4b lesions.
The first limitation of the present study is associated with the retrospective nature of the data analyses. Second, a small number of subjects were included in the study population. Last, there might be false-negative results in the biopsied lesions.

\section{CONCLUSION}

Our results show that BI-RADS C4b category had higher PPV for predicting malignancy compared to BI-RADS C4a category. Further studies are needed to determine more predictive factors for breast cancer.

\section{CONFLICT OF INTEREST}

No potential conflict of interest relevant to this article was reported.

\section{REFERENCES}

1. Ferlay J, Colombet M, Soerjomataram I, Mathers C, Parkin DM, Piñeros $\mathrm{M}$, et al. Estimating the global cancer incidence and mortality in 2018: GLOBOCAN sources and methods. Int J Cancer 2019;144:1941-53.

2. Choi KS, Yoon M, Song SH, Suh M, Park B, Jung KW, et al. Effect of mammography screening on stage at breast cancer diagnosis: results from the Korea National Cancer Screening Program. Sci Rep 2018;8:8882.

3. Lee EH, Park B, Kim NS, Seo HJ, Ko KL, Min JW, et al. The Korean guideline for breast cancer screening. J Korean Med Assoc 2015;58:408-19.

4. D'Orsi CJ. ACR BI-RADS Atlas: Breast Imaging Reporting and Data System. 5th ed. Reston: American College of Radiology; 2013.

5. Lazarus E, Mainiero MB, Schepps B, Koelliker SL, Livingston LS. BI-RADS lexicon for US and mammography: interobserver variability and positive predictive value. Radiology 2006;239: 385-91.

6. Itoh A, Ueno E, Tohno E, Kamma H, Takahashi H, Shiina T, et al. Breast disease: clinical application of US elastography for diagnosis. Radiology 2006;239:341-50.

7. Lakhani SR. WHO Classification of Tumours of the Breast. 4th ed. Lyon: International Agency for Research on Cancer; 2012.

8. Yoon JH, Kim MJ, Moon HJ, Kwak JY, Kim EK. Subcategorization of ultrasonographic BI-RADS category 4: positive predictive value and clinical factors affecting it. Ultrasound Med Biol 2011;37:693-9.

9. Kim EK, Ko KH, Oh KK, Kwak JY, You JK, Kim MJ, et al. 
Clinical application of the BI-RADS final assessment to breast sonography in conjunction with mammography. AJR Am J Roentgenol 2008;190:1209-15.

10. Elverici E, Barça AN, Aktaş H, Özsoy A, Zengin B, Çavuşoğlu M, et al. Nonpalpable BI-RADS 4 breast lesions: sonographic findings and pathology correlation. Diagn Interv Radiol 2015;21:189-94.

11. Li FS, Bai BY, Wang YM, Xiao Y, Song CX, Song ZJ, et al. Sonographic features of dense breast imaging reporting and data system 4 (BI-RADS-US4) for non-palpable breast lesions. Int J Clin Exp Med 2017;10:10806-12.

12. Costantini M, Belli P, Lombardi R, Franceschini G, Mulè A, Bonomo L. Characterization of solid breast masses: use of the sonographic breast imaging reporting and data system lexicon. J Ultrasound Med 2006;25:649-59; quiz 661.

13. Mohamed RE, Abo-Dewan KA. Incremental value of real-time ultrasound elastography in differentiating breast masses. Egypt J Radiol Nucl Med 2014;45:605-18.

14. Ikeda K, Ogawa Y, Takii M, Sugano K, Ikeya T, Tokunaga S, et al. A role for elastography in the diagnosis of breast lesions by measuring the maximum fat lesion ratio (max-FLR) by tissue Doppler imaging. Breast Cancer 2012;19:71-6.

15. Crystal P, Strano SD, Shcharynski S, Koretz MJ. Using sonography to screen women with mammographically dense breasts. AJR Am J Roentgenol 2003;181:177-82.

16. Lee HJ, Kim EK, Kim MJ, Youk JH, Lee JY, Kang DR, et al. Observer variability of Breast Imaging Reporting and Data System (BI-RADS) for breast ultrasound. Eur J Radiol 2008;65:293-8.

17. Stavros AT, Rapp CL, Parker SH. Breast Ultrasound. Philadelphia: Lippincott Williams \& Wilkins; 2004. 